\title{
Novel Pd Nanocubes Supported on Activated Carbon as a Catalyst for the Suzuki-Miyaura Coupling Reaction
}

\author{
Zhenpeng Shi ${ }^{1}$ and Xue-Feng Bai ${ }^{*}, 1,2$ \\ ${ }^{1}$ School of Chemistry and Material Science, Heilongjiang University, Harbin 150080, China \\ ${ }^{2}$ Institute of Petrochemistry, Heilongjiang Academy of Sciences, Harbin 150040, China
}

\begin{abstract}
Palladium nanocubes with diameters of $6 \sim 10 \mathrm{~nm}$ have been successfully synthesized by a simple reduction route with the assistance of PVP as stabilizing agent and $\mathrm{KBr}$ as a capping agent. The palladium nanocubes supported on activated carbon $(\mathrm{Pd} / \mathrm{C})$ were prepared by a physical absorption method. The-prepared $\mathrm{Pd} / \mathrm{C}$ catalysts were characterized by X-ray diffraction (XRD), transmission electron microscopy technology (TEM), thermogravimetric analyzer (TGA) and X-ray photoelectron spectroscopy (XPS). The results demonstrated that the palladium nano particles with the facecentered-cubic structure were uniformly supported on the activated carbon. It was shown from experimental results that the product yield for the Suzuki-Miyaura reaction between aryl bromides with aryl boronic acid attains more than $90 \%$ and has no significant loss of catalytic activity after five reaction cycles.
\end{abstract}

Keywords: Palladium nanocubes, Pd/C catalyst, Suzuki-Miyaura coupling reaction.

\section{INTRODUCTION}

Undoubtedly, for the pharmaceutical and fine chemical industry, the Suzuki-Miyaura cross-coupling reaction represents probably the most widely used carbon-carbon bond forming process [1]. Such reactions are usually catalyzed by noble Pd metal in the presence of many solids as a support [2]. Like many other catalysts, the activity and selectivity of Pd nanoparticles (NPs) often have a strong dependence on the size and shape (or more appropriately the facets or surface structures) [3]. In principle, one could tailor these parameters to maximize the catalytic performance of a Pd catalyst in an effort to reduce the loading of this precious and rare metal [4]. Therefore, the development of highperformance palladium catalysts for Suzuki-Miyaura crosscoupling reactions has been an important area of research and consequently, the synthetic methods with a rigorous size and shape control of the NPs have become the leading research focus [5-8].

Some previous researchers have made great efforts to explain that catalysts with well-defined shapes of metal nanocrystals supported with exposed distinct crystal facets have different performances [9-11]. However, the $\mathrm{Pd}$ catalysts currently used in the aforementioned reactions are mainly based on polycrystalline nanoparticles of Pd with poorly controlled sizes and shapes $[12,13]$. As such, they do not present a high catalytic performance. The catalytic selectivity for some reactions could be altered by adjusting the exposed facets of metal nanocrystals, while maximizing the catalytic performance and thus minimizing the loading, it is necessary to replace these nanoparticles with single-crystal

\footnotetext{
*Address correspondence to this author at the School of Chemistry and Material Science, Heilongjiang University, Harbin 150080, China; Fax: +86-451-82623693; E-mail: shizhnpeng@126.com
}

nanoparticles enclosed by a specific set of facets [14]. Recently, Xia et al. prepared Pd-Pt nanocrystals with different shapes such as cubes, tetrahedrons, and octahedrons, and then used them as catalysts for electrocatalytic activity to elucidate the dependence of catalytic activity on surface structure [15]. They found that the Pd-Pt concave nanocubes were four times more active for electrocatalytic activity and the (100)-facet-enclosed catalyst showed a higher activity, while the (111)-facet-enclosed held a better durability $[16,17]$. They, then reported that $\mathrm{Br}^{-}$ ions were found to absorb onto $\mathrm{Pd}\{100\}$ facets selectively with a coverage density of ca. 0.8 ions per surface $\mathrm{Pd}$ atom and without $\mathrm{Br}^{-}$, the $\{100\}$ facets could not be stabilized by the capping agent, leading to the formation of nanocubes with truncated corners $[18,19]$. Dai and Wang have prepared the catalysts of Pd cuboctahedron and tetrapod nanocrystals with $\mathrm{KBr}$ and hydrogen and carbon monoxide mixture as capping agents, respectively $[20,21]$. They found the Pd (111)-facetenclosed showed a higher activity on selective hydrongenation of acetylene and electro-oxidations of formic acid [22].

On the basis of these observations, we reported a simple and efficient method for synthesizing activated carbon-supported Pd nanoparticles as a catalyst. As stabilizing agent, the PVP (Polyvinylpyrrolidone) was reported for preventing the agglomeration of NPs, the Pd nanocubes were prepared in the presence of $\mathrm{KBr}$. Nanocube Pd supported on the activated carboncatalyst $(\mathrm{Pd} / \mathrm{C})$ was prepared by a mild and superior physical absorption method. In addition, the catalytic activities of $\mathrm{Pd} / \mathrm{C}$ in the Suzuki-Miyaura coupling action were studied.

\section{EXPERIMENTAL}

\subsection{Materials}

Polyvinylpyrrolidone (PVP, K30, MW=50,000) and $\mathrm{PdCl}_{2}$ (the metal salt used as precursors) were purchased from Sinopharm Chemical Reagent Co., Ltd. The citric acid 
(AR) and $\mathrm{KBr}(\mathrm{AR})$ were purchased from Tianjin Kermel. Benzeneboronic acid and aryl bromides were obtained from Yurui Chemical Co., Ltd. (Shanghai, China). All of these reagents were used without further purification. The activated carbon made from Coconut shell was obtained from Activated Carbon Company (Henan, China). Before used as a supporter, the activated carbon was treated by the oxidation with $\mathrm{HNO}_{3}$ at $353 \mathrm{~K}$.

\subsection{Preparation of Nanocube $P d / C$ Catalyst}

Solution A was prepared by dissolving $0.45 \mathrm{~g}$ of PVP and $0.13 \mathrm{~g}$ of $\mathrm{KBr}$ in $70.0 \mathrm{ml}$ of deionized water with vigorous stirring at $358 \mathrm{~K}$. Solution $\mathrm{B}$ was obtained by dissolving 0.05 $\mathrm{g}$ of $\mathrm{PdCl}_{2}$ and $0.03 \mathrm{~g}$ of $\mathrm{NaCl}$ in $10.0 \mathrm{ml}$ of deionized water under ultrasonic. The citric acid solution was added to the mixed solution of Solutions A and B at $353 \mathrm{~K}$ and stirred until the yellow solution of $\mathrm{PdCl}_{2} / \mathrm{PVP}$ changed to a brown color, which indicated the completion of chemical reduction. $1.0 \mathrm{~g}$ the above-treated activated carbon was added to the brown solution under constant stirring. Resulting catalyst was separated by centrifugation and washed three times with water and ethanol. The content of Pd from ICP analysis is $2.47 \%$ in the above-prepared $\mathrm{Pd} / \mathrm{C}$ catalyst.

\subsection{Characterization}

Thermogravimetric analysis (TGA) was performed on a Netzsch STA449C instrument from $30{ }^{\circ} \mathrm{C}$ to $800{ }^{\circ} \mathrm{C}$ at a heating rate of $10 \mathrm{~K} / \mathrm{min}$ in an air atmosphere. The X-ray diffraction (XRD) was measured on a Bruker D8 Advance $\mathrm{X}$-ray diffractometer using $\mathrm{Cu} \mathrm{K} \alpha$ irradiation $(\lambda=0.15418$ $\mathrm{nm})$ with the scanning speed of $0.5^{\circ} \%$ from $10^{\circ}$ to $70^{\circ}(2 \theta)$. Micro structural analyses were performed by transmission electron microscopy (JEOL JEM-2010 TEM, operating at $200 \mathrm{KV}$ with a point resolution of $0.23 \mathrm{~nm}$ ). X-ray photoelectron spectroscopy (XPS) measurements were carried out on a Thermo S Structural characterization of $\mathrm{Pd} / \mathrm{C}$ catalyst was recorded by cientific ESCALAB 250 . The analysis of the reaction products were performed on a Waters e2695-HPLC system by using an external standard method.

\subsection{General Procedure for Suzuki-Miyaura Coupling Reactions}

Aryl bromide $(1.0 \mathrm{mmol})$ and phenyl boronic acid (1.5 mmol) were added to a flask containing $\mathrm{Pd} / \mathrm{C}$ and $\mathrm{K}_{2} \mathrm{CO}_{3}(2$ mmol) in a mixture of $12 \mathrm{ml} \mathrm{H} \mathrm{H}_{2} \mathrm{O}: \mathrm{EtOH}(1: 1)$. The mixture was stirred in a water bath under $60^{\circ} \mathrm{C}$. After the completion of the reaction, the reaction mixture was cooled down to room temperature and mixed with $\mathrm{NaOH}(0.2 \mathrm{~mol} / 1,5 \mathrm{ml})$, and then extracted with ethyl to acetate $(10 \mathrm{ml})$. The yield of product was determined by means of HPLC.

\section{RESULTS AND DISCUSSION}

\subsection{Characterizations of the Activated Carbon- Supported Pd Nanocatalysts}

Like other cubic noble metals, the thermodynamically favorable shapes of Pd nanocrystals are cuboctahedron and multiply twinned particles [23]. To obtain an anisotropic nanostructure and new shapes, impurities or capping agents are generally employed to alter the surface free energies of nanoparticles. The capping agent bromide ions, has been widely employed in inducing new shapes. With bromide ions introduced into the reaction system, they may chemisorb onto the surface of Pd seed and alter the relative order of surface free energies [24]. Additionally PVP was employed as a stabilizing agent to prevent the aggregation of particles.

The $\mathrm{Pd} / \mathrm{C}$ catalyst and its precursor-Pd nano particles were characterized by TEM (Fig. 1a-d). Fig. (1a, b) show Pd nano particles prepared under the conditions without or with the existence of the bromide ions respectively. It was confirmed from TEM micrographs that the shape of the Pd nano particles prepared is an imperfect sphere and the diameter of these particles distribution is somewhat broad without the bromide ions (Fig. 1a). Compared with Fig. (1a), Pd nanoparticles with a uniform cube shape were obtained after bromide ions were introduced into reaction system (Fig. 1b). The average edge length of Pd nanocube was $7.3 \pm 2 \mathrm{~nm}$. A corresponding histogram of size distribution was shown in the inset of Fig. (1c). A small portion $(<10 \%)$ of the nanocubes was slightly elongated along one of the axes to form rectangular bars with aspect ratios (length to width) somewhat larger than one, but they are still nanocubes. It can be assumed from the above results that bromide ions play an important role in terms of selecting the Pd particle shape. It was observed from Fig. (1d) that the loading ratio is estimated to be higher than ca. $60 \%$.

The thermogravimetric analysis (TGA) curves (Fig. 2) reveal the superior thermal stability of both the activated carbon and $\mathrm{Pd} / \mathrm{C}$ up to $450{ }^{\circ} \mathrm{C}$. There is a $2.5 \%$ difference of the weight loss $\left(\Delta \mathrm{W}_{1}+\Delta \mathrm{W}_{2}\right)$ between activated carbon and $\mathrm{Pd} / \mathrm{C}$ was close to Pd content of $2.47 \%$ from ICP analysis.

Fig. (3) shows the XRD patterns of Pd nanoparticles, the activated carbon supporter and $\mathrm{Pd} / \mathrm{C}$ catalyst. The diffraction peak at $2 \theta=24.4^{\circ}$ and $43.5^{\circ}$ in both active carbon and $\mathrm{Pd} / \mathrm{C}$ catalyst is attributed to the carbon support. In addition to the peak of carbon, there were some other diffraction peaks in the $\mathrm{Pd} / \mathrm{C}$ catalyst and $\mathrm{Pd}$ nanoparticles. The diffraction peaks at $2 \theta=40.1^{\circ}, 46.7^{\circ}$ and $68.1^{\circ}$ in both of Pd nanoparticles and $\mathrm{Pd} / \mathrm{C}$ catalysts are characteristics of the face-centered-cubic (fcc) Pd, corresponding to the facets (111), (200) and (220), respectively. It was revealed that the Pd nanoparticles have been loaded onto carbon successfully. The average crystallite sizes of the Pd nanoparticles on the Pd/C catalyst can be estimated by using the Scherrer equation after background subtraction. In the XRD pattern of the $\mathrm{Pd} / \mathrm{C}$ catalyst, the (220) diffraction peak at $2 \theta=68.1^{\circ}$ of $\mathrm{Pd}$ was far from the background signal and thus it was chosen for the calculation. The average crystallite size was about $7.6 \mathrm{~nm}$ for the $\mathrm{Pd} / \mathrm{C}$. These values are the same as that observed by TEM.

Fig. (4) shows the XPS spectrum of the Pd/C catalyst for identifying the oxidation state of the surface-loaded Pd NPs. It was observed from Fig. (4) that there were two distinct peaks with binding energies of 335.6 and $341 \mathrm{eV}$, which can be assigned to the signals of $3 \mathrm{~d}_{5 / 2}$ and $3 \mathrm{~d}_{3 / 2}$ of $\mathrm{Pd}^{0}$, respectively. The binding energy difference of the two peaks is $5.4 \mathrm{eV}$, which is in accordance with the theoretical value. Therefore, the XPS analysis indicates that the in situ formed $\mathrm{Pd}^{0}$ were thoroughly reduced to be neutral. 

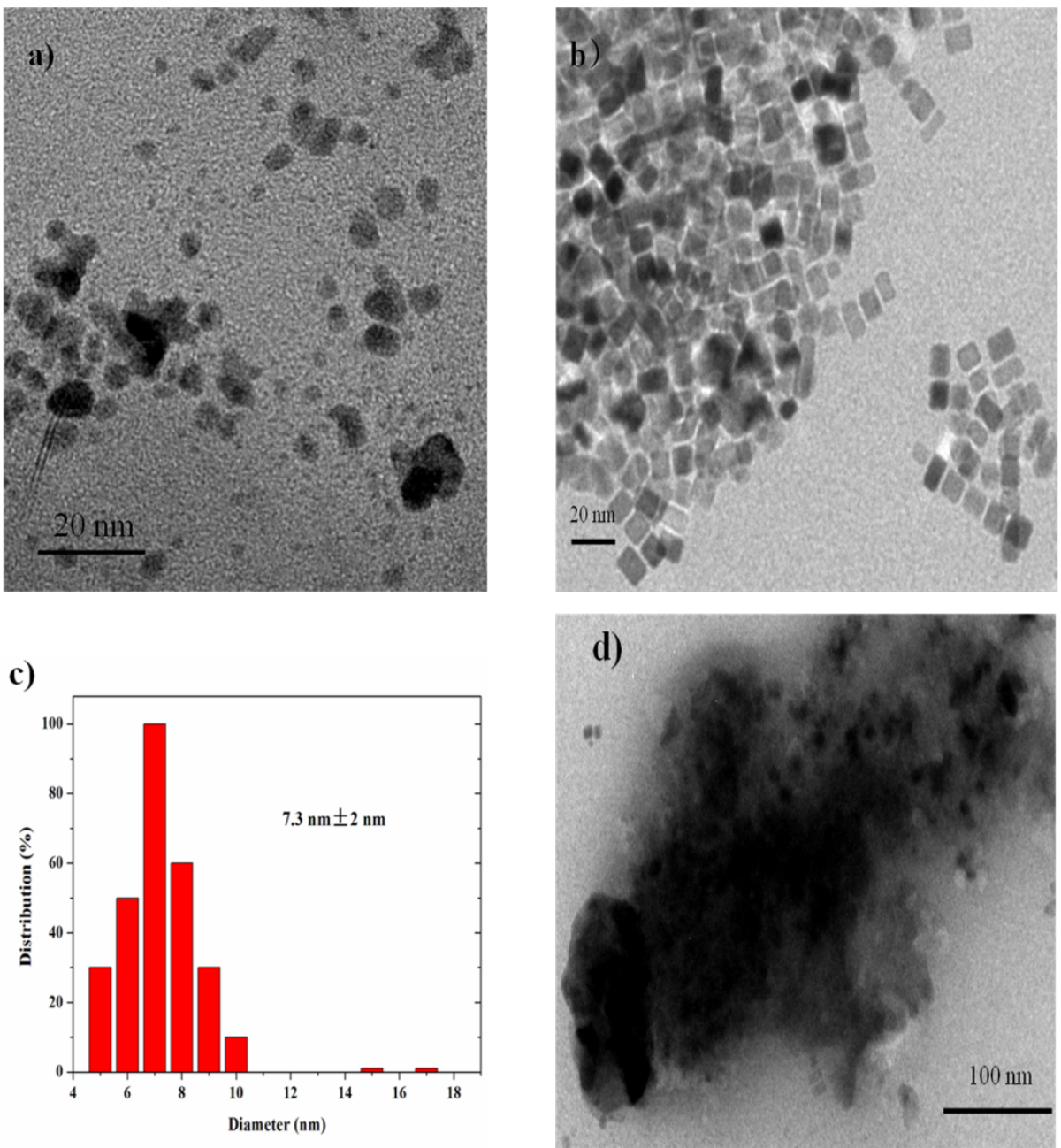

Fig. (1). TEM images of $\mathrm{Pd} / \mathrm{C}$ catalyst and its precursor-Pd nano particles. (a) and (b) TEM images of Pd nanoparticles and Pd nanocube. (c) The diameter distribution histogram of Pd nanocubes. (d) TEM images of $\mathrm{Pd} / \mathrm{C}$ catalyst.

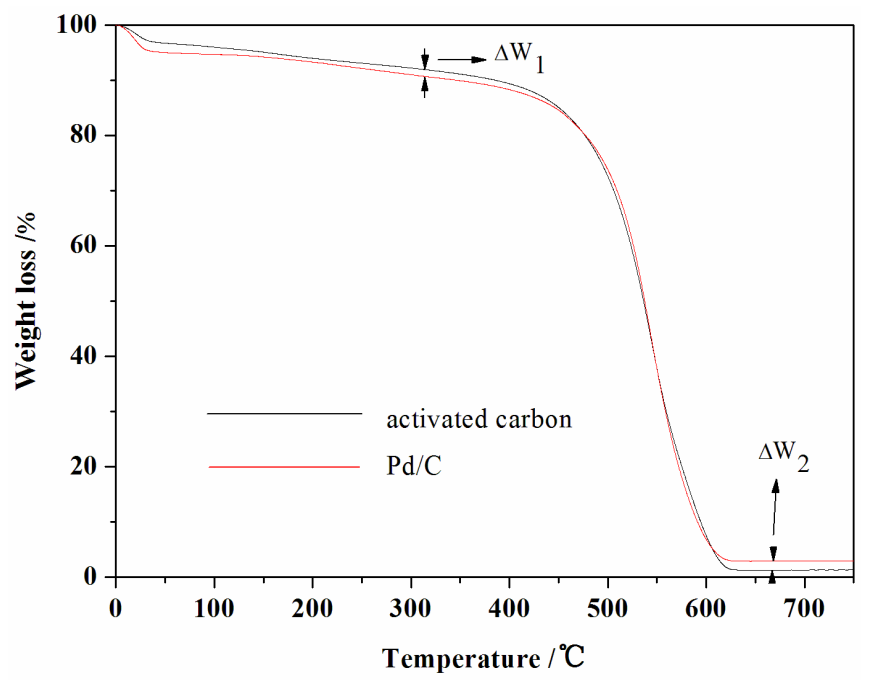

Fig. (2). TGA curve of activated carbon and $\mathrm{Pd} / \mathrm{C}$ catalyst.

\subsection{Catalytic Activity of the Nanocube Pd/C Catalyst}

To evaluate the catalytic efficiency of the-above prepared nanocube $\mathrm{Pd} / \mathrm{C}$ catalyst, a series of Suzuki-Miyaura cross- coupling reactions were carried out and the results are presented in Table $\mathbf{1}$.

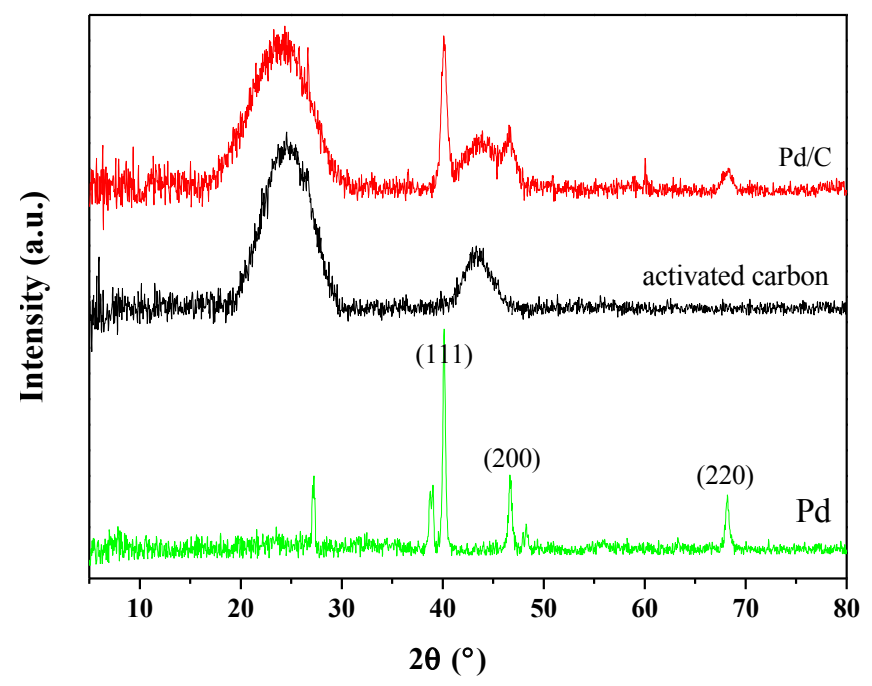

Fig. (3). XRD patterns of $P d$ nanocube, activated carbon and $P d / C$.

High yields were easily obtained in a short time at room temperature when aryl iodides were used ( $>99 \%$ for HPLC 
yield, entries 1-2 in Table 1). It is well known that electronic effects strongly affect the Suzuki-Miyaura cross-coupling reactions. Compared with electron-rich para-substituted aryl halides, electron-deficient para-substituted aryl halides show high activity in the process of coupling with arylboronic acids due to the activation of the benzene ring as well as the ease of the charge-transfer, while it is the opposite in the case of para-substituted arylboronic acids. However, high catalytic activities were observed for both electron-rich and electron-deficient para-substituted aryl bromides under a relatively mild condition $\left(60{ }^{\circ} \mathrm{C}\right.$ for $0.5-1.0 \mathrm{~h}$ in air), and good yields of different cross-coupling products were approached ( $>91 \%$ for HPLC yield, entries 3-8 in Table 1). When the less active aryl chloride was employed, a HPLC yield of $74 \%$ and $65 \%$ was observed $\left(90{ }^{\circ} \mathrm{C}\right.$ for $10 \mathrm{~h}$ in air, entry 9-10 in Table 1). The yield of chlorobenzene achieved $53 \%\left(90{ }^{\circ} \mathrm{C}\right.$ for $20 \mathrm{~h}$ in air, entry 11 in Table 1). That is, the prepared nanocube $\mathrm{Pd} / \mathrm{C}$ catalyst has very high activity for the coupling of aryl chloride and aryl boronic acids.

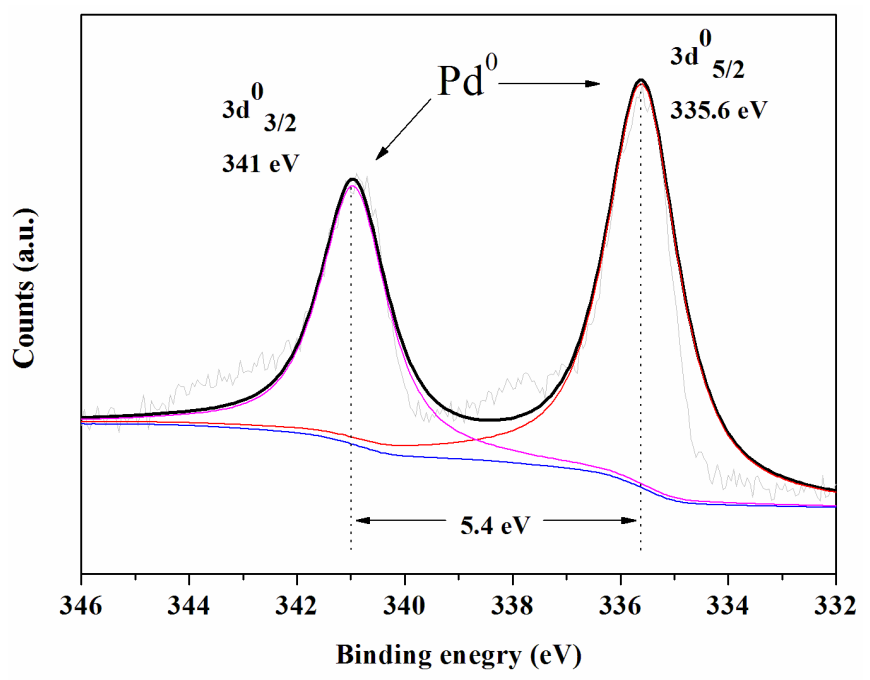

Fig. (4). XPS spectrum of $\mathrm{Pd} / \mathrm{C}$ catalyst.

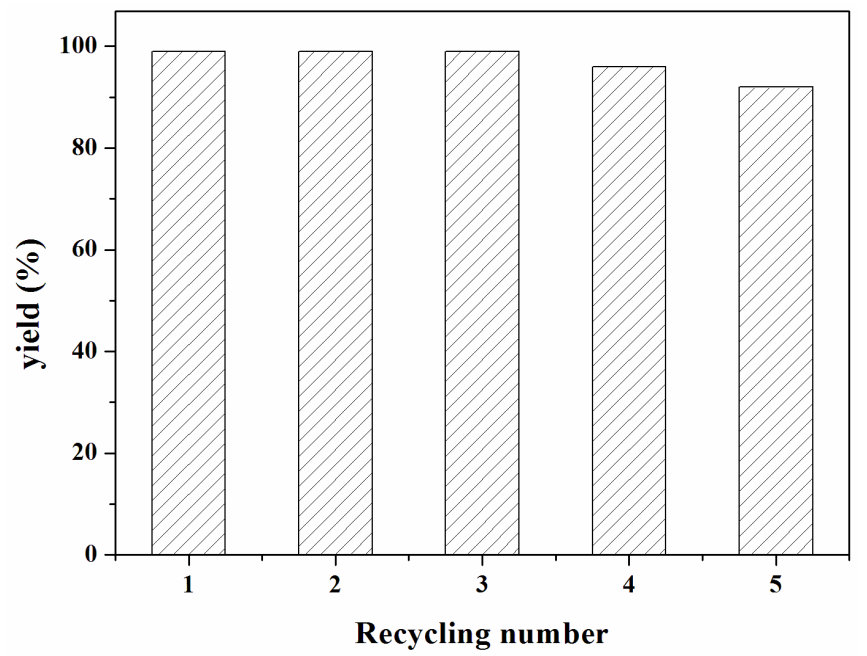

Fig. (5). Recycling test of nanocube $\mathrm{Pd} / \mathrm{C}$.

To evaluate the recycling efficiency, the Suzuki-Miyaura cross-coupling raections with para-bromoacetophenone and phenyboronic acid over the prepared nanocube $\mathrm{Pd} / \mathrm{C}$ were carried out under the same condition as entry 4 of Table 1 (except $1 \mathrm{~h}$ ) for five times and the results are shown in Fig. (5). The catalyst could be separated from products by simple phase separation and recycled for five times without evident loss of activity.

Table 1. Representative Suzuki-Miyaura cross-coupling reactions over nanocube $\mathrm{Pd} / \mathrm{C}$ catalyst $^{\mathrm{a}}$.

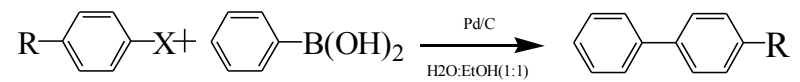

\begin{tabular}{|c|c|c|c|c|c|}
\hline Entry & $\mathbf{X}$ & $\mathbf{R}$ & $\mathrm{T} /{ }^{\circ} \mathbf{C}$ & Time/h & Yield ${ }^{\mathrm{b}} / \%$ \\
\hline 1 & I & $-\mathrm{OCH}_{3}$ & 40 & 0.5 & 99 \\
\hline 2 & I & $-\mathrm{H}$ & 40 & 0.5 & 99 \\
\hline 3 & $\mathrm{Br}$ & $-\mathrm{NO}_{2}$ & 60 & 0.5 & 99 \\
\hline 4 & $\mathrm{Br}$ & $-\mathrm{COCH}_{3}$ & 60 & 0.5 & 98 \\
\hline 5 & $\mathrm{Br}$ & $-\mathrm{CN}$ & 60 & 0.5 & 96 \\
\hline 6 & $\mathrm{Br}$ & $-\mathrm{OCH}_{3}$ & 60 & 0.5 & 91 \\
\hline 7 & $\mathrm{Br}$ & $-\mathrm{H}$ & 60 & 1.0 & 98 \\
\hline 8 & $\mathrm{Br}$ & $-\mathrm{CH}_{3}$ & 60 & 1.0 & 92 \\
\hline 9 & $\mathrm{Cl}$ & $-\mathrm{NO}_{2}$ & 90 & 10 & 74 \\
\hline 10 & $\mathrm{Cl}$ & $-\mathrm{COCH}_{3}$ & 90 & 10 & 65 \\
\hline 11 & $\mathrm{Cl}$ & $-\mathrm{H}$ & 90 & 20 & 53 \\
\hline
\end{tabular}

\section{CONCLUSION}

Pd nanocubes with controllable size and shape have successfully been prepared with the assistance of PVP as a stabilizing agent and $\mathrm{KBr}$ as a capping agent. $\mathrm{KBr}$ and $\mathrm{PVP}$ were found to play an important role in the formation and size of $\mathrm{Pd}$ nanocubes, respectively. The nanocube $\mathrm{Pd} / \mathrm{C}$ catalyst exhibits high catalytic activity and good stability in the Suzuki-Miyaura cross-coupling reaction. The catalytic activity of nanocube $\mathrm{Pd} / \mathrm{C}$ catalyst was found to have no evident loss after five catalytic cycles. Therefore, this new nanocube $\mathrm{Pd} / \mathrm{C}$ catalyst with the advantages of high efficiency and good recyclability will become a promising candidate for potential applications in industrial synthesis.

\section{CONFLICT OF INTEREST}

The authors confirm that this article content has no conflict of interest.

\section{ACKNOWLEDGEMENTS}

We gratefully acknowledge the financial support provided by the National international cooperation projects of China (Grant No. 2011DFR50310).

\section{REFERENCES}

[1] Xia YN, Yang PD, Sun YG, et al. One-dimensional nanostructures: synthesis, characterization, and applications. Adv Mater 2003; 15: 353-89. 
[2] Liebscher J, Yin LX. Carbon-carbon coupling reactions catalyzed by Heterogeneous palladium. Chem Rev 2007; 107: 133-73.

[3] Molnar A. Efficient, selective, and recyclable palladium catalysts in carbon-carbon coupling reactions. Chem Rev 2011; 111: 2251320.

[4] Jana R, Pathak TP, Sigman MS. Advances in transition metal (Pd, $\mathrm{Ni}, \mathrm{Fe}$ )-catalyzed cross-coupling reactions using alkyl-organometallics as reaction partners. Chem Rev 2011; 111: 1417-92.

[5] Huo CL, Yang HM. Preparation and enhanced photocatalytic activity of $\mathrm{Pd}-\mathrm{CuO} /$ palygorskite nanocomposites. Applied Clay Sci 2013; 74: 87-94.

[6] Kim SK, Kim C, Lee JH, Kim J, Lee H, Moon SH. Performance of shape-controlled Pd nanoparticles in the selective hydrogenation of acetylene. J Catal 2013; 306: 146-54.

[7] Jung K, Riaz A, Lee $\mathrm{S}$, et al. Urchin-like $\alpha-\mathrm{MnO}_{2}$ decorated with $\mathrm{Au}$ and $\mathrm{Pd}$ as bi-functional catalyst for rechargeable lithiumoxygen batteries. J of Power Source 2013; 244: 328-35.

[8] Ren MJ, Chen J, Li Y, et al. Lattice contracted Pd-hollow nanocrystals: synthesis, structure and electro catalysis for formic acid oxidation. J Power Source 2014; 246: 32-8.

[9] Zhang HJ, Lu LL, Cao YN, Du S, Cheng Z, Zhang SW. Fabrication of catalytically active $\mathrm{Au} / \mathrm{Pt} / \mathrm{Pd}$ trimetallic nanoparticles by rapid injection of $\mathrm{NaBH}_{4}$. Mater Res Bull 2014; 49: 393-8.

[10] Shen C, Wang YJ, Xu JH, Wang K, Luo GS. Size control and catalytic activity of highly dispersed $\mathrm{Pd}$ nanoparticles supported on porous glass beads. Langmuir 2012; 28: 7519-27.

[11] Yarulin A, Yuranov I, Cardenas LF, Abdulkin P, Kiwi ML. Sizeeffect of Pd-(poly (N-vinyl-2-pyrrolidone)) nanocatalysts on selective hydrogenation of alkynols with different alkyl chains. J Phys Chem C 2013; 117: 13424-34.

[12] $\mathrm{Qu}$ KG, Wu L, Ren JS, Qu XG. Natural DNA-modified grapheme/Pd nanoparticles as highly active catalyst for formic acid electro-oxidation and for the Suzuki reaction. ACS Appl Mater Interfaces 2012; 4: 5001-9.

[13] Chang CM, Hon MH, Leu IC. Outstanding $\mathrm{H}_{2}$ sensing performance of $\mathrm{Pd}$ nanoparticle-decorated $\mathrm{ZnO}$ nanorod arrays and the temperature-dependent sensing mechanisms. ACS Appl Mater Interfaces 2013; 5: 135-43.

[14] Gu H, Yang Y, Tian JX, Shi GY. Photochemical synthesis of noble metal (Ag, Pd, Au, Pt) on graphene/ZnO multihybrid nanoarchitec- tures as electrocatalysis for $\mathrm{H}_{2} \mathrm{O}_{2}$ reduction. ACS Appl Mater Interfaces 2013; 5: 6762-8.

[15] Zhang N, Xu YJ. Nanochemistry-derived Bi2WO6 nanostructures: towards production of sustainable chemicals and fuels induced by visible light. Chem Mater 2013; 25: 1979-88.

[16] Zhang H, Jin MS, Xiong YJ, Lim B, Xia YN. Shape-controlled synthesis of $\mathrm{Pd}$ nanocrystals and their catalytic applications. Acc Chem Res 2013; 46: 1783-94.

[17] Xie SF, Peng HC, Lu N, et al. Confining the Nucleation and Overgrowth of $\mathrm{Rh}$ to the $\{111\}$ Facets of Pd nanocrystal Seeds: The Roles of Capping Agent and Surface Diffusion. J Am Chem Soc. 2013; 135: 16658-67.

[18] Nguyen VL, Ohtaki M, Matsubara T, Cao MT, Nogami M. New experimental evidences of Pt-Pd bimetallic nanoparticles with coreshell configuration and highly fine-ordered nanostructures by highresolution electron transmission microscopy. J Phys Chem C 2012; 116: $12265-74$

[19] Jin MS, Zhang H, Xie ZX, Xia YN. Palladium nanocrystals enclosed by $\{100\}$ and $\{111\}$ facets in controlled proportions and their catalytic activities for formic acid oxidation. Energy Environ Sci. 2012; 5: 6352-7.

[20] Dai Y, Mu XL, Tan YM, et al. Carbon monoxide-assisted synthesis of single-crystalline $\mathrm{Pd}$ tetrapod nanocrystals through hydride formation. J Am Chem Soc 2012, 134: 7073-80.

[21] Wang SB, Zhu W, Ke J, Lin M, Zhang YW. Pd-Rh nanocrystals with tunable morphologies and compositions as efficient catalysts toward Suzuki cross-coupling reactions. ACS Catal 2014; 4: 2298306.

[22] Zhang H, Jin MS, Liu HY, et al. Facile synthesis of Pd-Pt alloy nanocages and their enhanced performance for preferential oxidation of CO in excess hydrogen. ACS Nano 2011; 5: 8212-22.

[23] Lim U, Kobayashi H, Yu T, et al. Synthesis of Pd-Au bimetallic nanocrystals via controlled overgrowth. J Am Chem Soc 2010; 132: 2506-7.

[24] Zhu C, Zeng J, Tao J, et al. Kinetically controlled overgrowth of $\mathrm{Ag}$ and $\mathrm{Au}$ on $\mathrm{Pd}$ nanocrystal seeds: from hybrid dimmers to nonconcentric and concentric bimetallic nanocrystals. J Am Chem Soc 2012; 134: 15822-31. 